UCRL-JC-121130

PREPRINT
CDNF-9510/43-3

\title{
Ablative Material Removal Utilizing the Copper Vapor Laser
}

B. E. Warner, C. D. Boley, J. J. Chang, E. P. Dragon,

M. A. Havstad, M. Martinez, W. McLean II

\section{RECEIVED \\ OCT 061995 \\ OSTI}

This paper was prepared for submittal to the

LEOS '95 8th Annual Meeting 1995 IEEE LEOS Annual Meeting

San Francisco, CA

October 30-November 2, 1995

August 1995

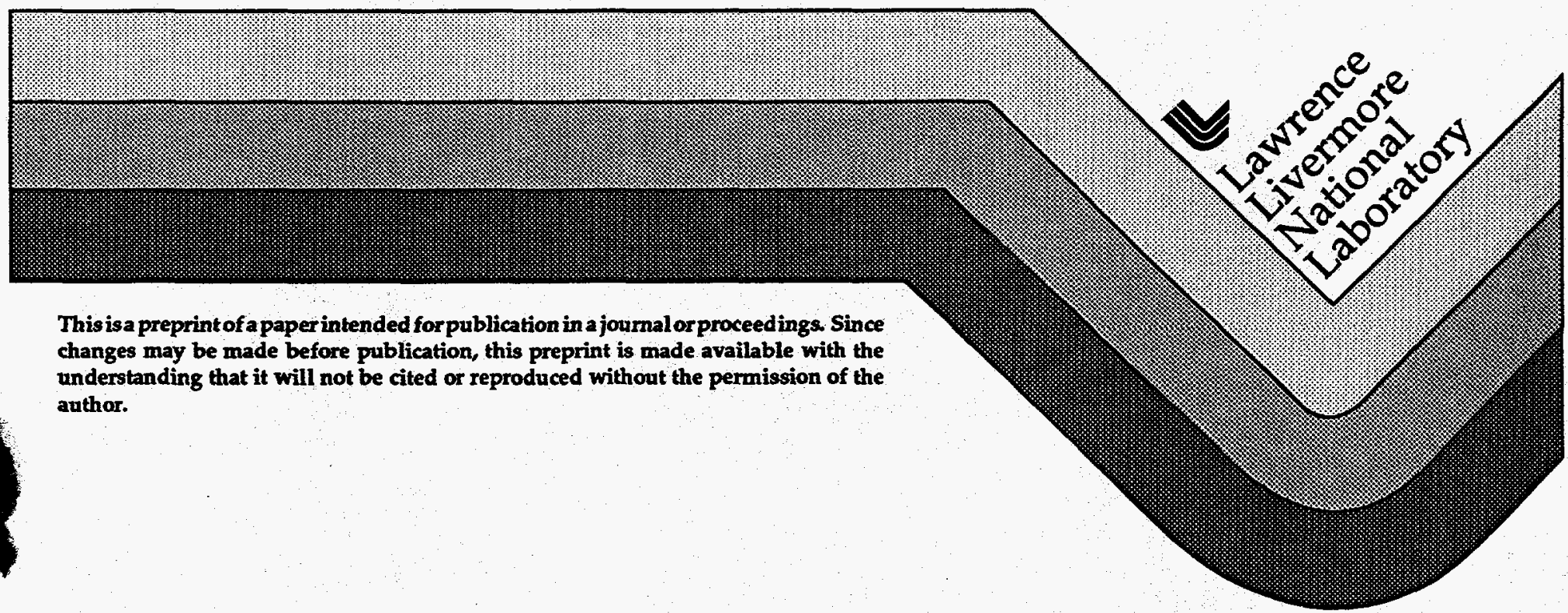




\section{DISCLAIMER}

This document was prepared as an account of work sponsored by an agency of the United States Government. Neither the United States Government nor the University of California nor any of their employees, makes any warranty, express or implied, or assumes any legal liability or responsibility for the accuracy, completeness, or usefulness of any information, apparatus, product, or process disclosed, or represents that its use would not infringe privately owned rights. Reference herein to any specific commercial products, process, or service by trade name, trademark, manufacturer, or otherwise, does not necessarily constitute or imply its endorsement, recommendation, or favoring by the United States Government or the University of California. The views and opinions of authors expressed herein do not necessarily state or reflect those of the United States Government or the University of California, and shall not be used for advertising or product endorsement purposes.

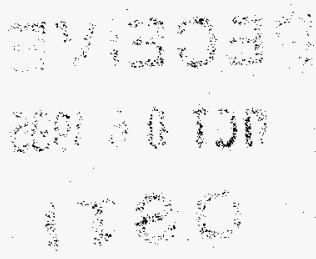




\section{DISCLAIMER}

Portions of this document may be illegible in electronic image products. Images are produced from the best available original document. 


\title{
ABLATIVE MATERIAL REMOVAL UTILIZING THE COPPER VAPOR LASER
}

\author{
Bruce E. Warner, Charles D. Boley, Jim J. Chang, Ernest P. Dragon, \\ Mark A. Havstad, Mark Martinez, and William McLean II \\ Lawrenee Livermore National Laboratory \\ P.O. Box 5508, MS L-467, Livermore, CA 94551, USA
}

Since its invention in the late 1960 s, the copper vapor laser has been developed predominantly for laser isotope separation. ${ }^{1}$ In this application the laser is valued because of its visible wavelength, $50 \mathrm{~ns}$ pulses, multi-kilohertz repetition rate, and $1-2 \%$ electrical to optical efficiency. As this laser system has matured into an industrial tool, new material processing applications for the laser have developed. When applied to materials processing, the visible wavelength is found to couple well to most materials, the short pulse length causes ablative material removal, and the high repetition rate increases the material removal rate to a moderate level. A further advantage of the laser is near diffraction-limited operation at hundreds of watts average power, allowing precise spatial control.

Over the past couple of years LLNL has investigated both a one-dimensional model and experimental measurements of copper laser beam/material interactions. The model involves a onedimensional description of heat transport below a surface, hydrodynamic expansion of the vapor and compressed air, and light propagation through the vapor to the vaporization surface. ${ }^{2,3}$ Laser light strikes the surface, causing a melt layer to develop and propagate inward into the solid material. When the vaporization temperature is reached, the vapor begins to blow off, preceded by a plug of compressed air. This is bounded by a shock front. When the temperature becomes sufficiently high, both the incident beam and the reflected beam (to the extent that it is appreciable) can be absorbed in the vapor by photoionization and inverse bremsstrahlung. Figures la displays modeled bulk temperatures versus time. Figure $1 \mathrm{~b}$ displays a Schlieren image at $\mathrm{t}=50 \mathrm{~ns}$ indicating a laser produced spherical vapor expansion with a laser detonation front.

Laser drilling has been widely used in industry because of its high production rate, ability to rapidly vary hole size, ability to drill holes at shallow angles, and ability to drill traditionally hard to work materials such as ceramics and composite materials. We have extended this utility to sub-millimeter dimensions by use of a near diffraction-limited copper laser and precision wave front tilting technology. In our investigation, laser trepanning is achieved by tilting the $\mathrm{X}-\mathrm{Y}$ scanning mirror sinusoidally such that the laser spot generates a circular pattem on the work piece. Trepanned holes down to 50 microns in diameter have been drilled this way.

Figure 2a illustrates three CVL trepanned holes with 185 micron diameter in $1 \mathrm{~mm}$ stainless steel. Measurements indicate that both the entrance and exit hole have a roundness error of about 5 microns caused by various mechanisms. The nature of the laser/material interaction, discussed above, leads to ablative material removal from these deep holes with negligible heat affected zones, less than 1 micron in most cases. Copper laser trepanning represents a great potential in laser precision micro-drilling. Noncircular holes have been drilled by simply changing the laser scanning pattern. The hole quality drilled by this laser micro-machining system is found to be comparable or better than holes drilled by electric discharge machining (EDM). With the flexibility in hole geometry and size, and scalability to higher speed, this micro-machining system offers a superior technique to EDM machines which currently are widely used in industry.

The same virtues that make the copper laser a good drilling source also make it a good source for pulsed laser deposition (PLD). LLNL has utilized $100-200 \mathrm{~W}$ copper lasers to vaporize carbon from a graphite target, producing diamond-like-carbon (DLC) thin films. Since the pulse repetition rate of the laser is several kilohertz, we can deposit films at $10-50$ times other reported PLD rates. Figure $2 b$ displays the spatial distribution of the DLC after $10^{5}$ laser shots ( 23 seconds). The properties of these films indicate high value for electronics, chemical resistance, and tribological applications. In addition to carbon, there are many high-value thin film materials that may provide a significant market for copper laser technology. 
(a)

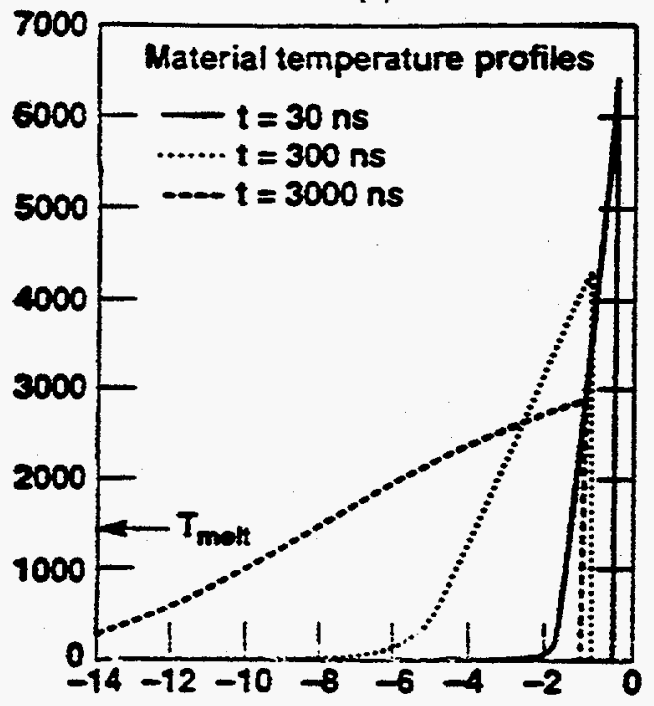

Laser induced detonation wave

Primary vapor plume

Figures 1. (a) Temperature profiles of the stainless steel material. Note $\mathrm{z}$ is the dimension into the surface.

(b) Shadow image of a copper laser produced vapor plume from an aluminum target at a laser intensity of $7.3 \times 10^{9}$ $\mathrm{W} / \mathrm{cm}^{2}$.
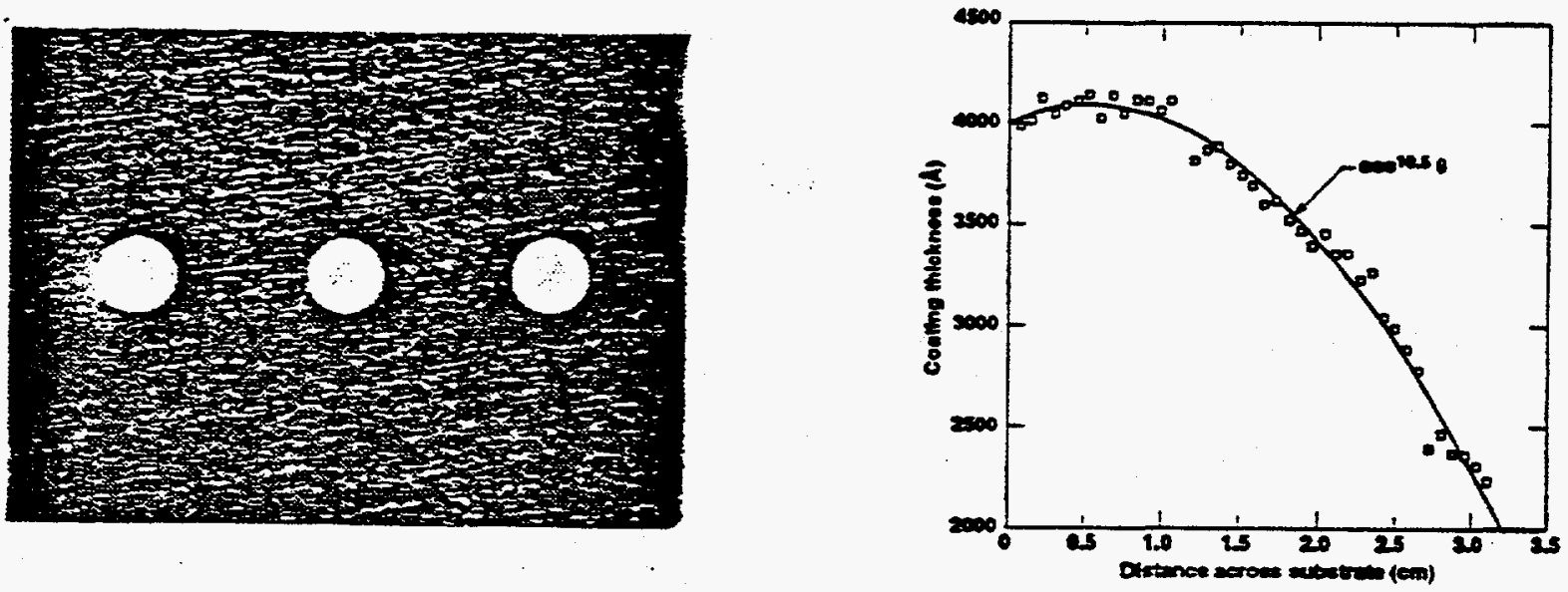

Figures 2. (a) Precision laser trepanned holes with hole diameter of -200 microns. (b) DLC Spatial distribution after $10^{5}$ shots.

Acknowledgments

The authors would like to thank E. Fehring, G. Huete, and C. Cochran for excellent technical support and M. Balooch for outstanding AFM measurements. This work was performed under the auspices of the U.S. Department of Energy by Lawrence Livermore National Laboratory under contract no. W-7405-Eng-48.

References

1. Wamer, B.,(1987) Overview of Copper-Laser Development for Isotope Separation, Proceedings of SPIE - Society of Photo-Optic Instrumentation Engineers Vol. 737, 2 - 6.

2. Boley, C. and Early, J. (1994) Computational Model of Drilling with High Radiance Pulsed Lasers, Paper presented at the International Congress on Application of Lasers \& Electro-Optics (ICALEO).

3. Kar, A., and Mazumbder, J. (1994) A Mathematical Model for Nanoscale Particles Formed During Laser Ablation, Physics Review E 49, 410-419. 